\title{
Defensive responding and leverpress topography compatibility: Effects of shock intensity, S-S interval, and lever position
}

\author{
RONALD C. FELDT and LEE I. McCANN \\ University of Wisconsin-Oshkosh, Oshkosh, Wisconsin 54901
}

\begin{abstract}
The degree of compatibility between defensive responding and leverpress topography was investigated. Rats were trained to leverpress on a Sidman avoidance schedule for one 60-min session. Measures of defensive responding (jumping and rearing) were recorded during initial training. Shock intensity $(.5,1.0$, and $2.0 \mathrm{~mA})$ and S-S interval $(1,3$, and $5 \mathrm{sec})$ were varied in Experiment 1. S-S interval had no effect on defensive responding or on performance. Rate of jumping was an increasing function of intensity only at lower intensities. Both jumping and rearing were significantly correlated with leverpressing. Shock intensity $(1.0$ and $2.0 \mathrm{~mA})$ and lever position $(3.02$ and $16.83 \mathrm{~cm}$ ) were varied in Experiment 2. Response rate was an increasing function of intensity at the high lever position but not at the low position. Correlations between rearing and leverpressing, and between jumping and leverpressing, were not significant for either lever position. Bolles' (1970) theory of species-specific defense reactions was invoked to account for initial facilitated performance.
\end{abstract}

According to Bolles' (1970) theory of speciesspecific defense reactions, the rapidity with which an avoidance response is acquired is determined by the degree of compatibility between the topography of the response and that of the defensive reaction to shock. Since leverpressing is not a species-specific defense reaction, the reported difficulty in acquisition of the leverpress avoidance response, in contrast to the more easily acquired hurdle-jumping response (Riess, 1971), may be explained through noncompatibility.

Bolles and Popp (1964) have reported that rats "that explore, rear, and attempt to climb the walls" (p. 317) learn leverpress avoidance more readily than those that freeze or run. Riess and Farrar (1972) attributed facilitated leverpress acquisition at higher shock intensities to more vigorous activity and jumping; they reported that initial acquisition responding was of a "short latency . . . 'lurch' toward the bar" (p. 352), indicating the importance of shock-elicited behavior in facilitating leverpress acquisition. Shockelicited jumping also increases with shock intensity (Kimble, 1955; Trabasso \& Thompson, 1962), supporting the assumption that shock intensity is a relevant variable in the elicitation of leverpresscompatible responding.

The S-S interval is also involved. Cahoon and Crosby (1969) have reported that a leverpress response can be more rapidly acquired when termination of continuous shock $(\mathrm{S}-\mathrm{S}$ interval $=0)$

Requests for reprints should be sent to Lee I. McCann, Department of Psychology, University of Wisconsin-Oshkosh, Oshkosh, Wisconsin 54901 . is contingent upon it, and Leaf (1965) has shown that shorter S-S intervals facilitate leverpress acquisition. Higher shock density apparently promotes more defensive responding which is compatible with leverpressing, thus facilitating acquisition.

\section{EXPERIMENT 1}

The purpose of Experiment 1 was to investigate the effects of shock intensity and S-S interval on jumping and rearing - two defensive reactions which, in contrast to freezing and running, are highly compatible with leverpressing-and on leverpress acquisition during a 60-min training session in the Sidman avoidance situation. The correlation between these defensive response measures and leverpress performance was also determined.

\footnotetext{
Method

Subjects. The rats were 54 experimentally naive male albinos of the Sprague-Dawley strain, approximately 120-150 days old and maintained on ad-lib food (Purina Laboratory Chow) and water in individual cages $(24.13 \times 17.78 \times 17.78 \mathrm{~cm})$.

Apparatus. A Lehigh Valley Electronics operant chamber (Model 1417; interior dimensions, $30.48 \times 24.13 \times 26.67 \mathrm{~cm}$ ) was used. The front and rear panels were stainless steel with sides and top of transparent acrylic. The floor consisted of 16 stainless steel rods, $.46 \mathrm{~cm}$ in diameter, placed $1.90 \mathrm{~cm}$ center to center. The lever was positioned $16.83 \mathrm{~cm}$ above the grid floor in the right half of the chamber, $.32 \mathrm{~cm}$ from the side, and was activated by a weight of $30 \mathrm{~g}$. The jewel lights above the lever and the food cup were removed and the holes covered.

An insulated cubicle (Model $1417 \mathrm{C}$, Lehigh Valley Electronics) housed the chamber. It was equiped with an exhaust blower and a one-way observation window $(17.78 \times 20.32 \mathrm{~cm})$. The interior was illuminated by a General Electric $28-\mathrm{V}$ bulb (1829) with a separate power source.
} 
Two $.80-\mathrm{cm}$ transparent acrylic sheets $(25.08 \times 17.54 \mathrm{~cm}$ and $25.08 \times 9.52 \mathrm{~cm}$ ) were joined to form a "corner" and positioned in the right half of the chamber. The device was similar to that of Cahoon and Crosby (1969) and was used to limit the rat's activity within an area of $17.78 \times 10.32 \mathrm{~cm}$, thus increasing the probability of lever contact.

A Grason-Stadler shock generator with scrambler (Model E1064GS) was used. Grason-Stadler relay equipment was located in an adjacent room for programming and recording.

Procedure. A 3 by 3 by 4 factorial design was employed, with Shock Intensity $(.5,1.0$, and $2.0 \mathrm{~mA})$, S-S Interval $(1,3$, and $5 \mathrm{sec}$ ), and Blocks (15 min) of training as factors. Rats were trained on a Sidman avoidance schedule with an R-S interval of $20 \mathrm{sec}$ and shock duration of $.5 \mathrm{sec}$. A leverpress did not terminate the $.5-\mathrm{sec}$ shock. Rats were randomly assigned to the treatment groups.

Each rat was placed in the chamber, with houselight on and exhaust blower operating, for 5 min prior to avoidance training. Total rearing time (recorded by activating a stopclock when any part of the rat's anatomy, excluding tail, was above a painted line identifying a horizontal plane $14.0 \mathrm{~cm}$ above the grid with rear feet on the grid) and jumping (leaping from the grid and raising any part of the rat's anatomy, excluding tail, above the $14.0-\mathrm{cm}$ plane) were measured through the $10 \mathrm{th}$ leverpress. Two observers were used periodically for reliability estimation. Leverpresses and shocks received were totaled at 15 -min intervals, and the session was terminated after $60 \mathrm{~min}$ of training.

\section{Results}

Each frequency score for jumping and total time rearing was divided by the amount of time expired through the 10th leverpress. These data were analyzed by a 3 by 3 (Intensity by S-S Interval) ANOVA. Performance measures were analyzed by a 3 by 3 by 4 (Intensity by S-S Interval by Blocks) ANOVA with repeated measures on Blocks. The Pearson product moment coefficients of correlation between the observers for jumping and rearing were .99 and .92 , respectively.

Intensity revealed the only significant effect on jumping, $F(2,45)=7.68, p<.01$, and rearing, $\mathrm{F}(2,45)=6.84, \mathrm{p}<.01$. The means of jumping (frequency $/ \mathrm{min}$ ) at $.5,1.0$, and $2.0 \mathrm{~mA}$ were .47 , 1.34 , and 2.19 , respectively, with only .5 and $2.0 \mathrm{~mA}$ differing significantly, $\mathrm{p}<.01$. The means for rearing (total time $/ \mathrm{min}$ ) at $.5,1.0$, and $2.0 \mathrm{~mA}$ were $7.24,12.30$, and 10.07 , respectively, with only .5 and $1.0 \mathrm{~mA}$ differing significantly, $\mathrm{p}<.01$.

For performance measures, response rate (per minute) was an increasing function of Intensity, $F(2,45)=24.42, p<.01$, and Blocks, $F(3,135)=$ $5.56, \mathrm{p}<.01$. Analysis of shock rate (per minute) indicated significant effects for Intensity, $F(2,45)=$ $11.21, \mathrm{p}<.01, \mathrm{~S}-\mathrm{S}$ Interval, $\mathrm{F}(2,45)=7.86, \mathrm{p}<.01$, Blocks, $F(3,135)=27.91, p<.01$, and the $S-S$ Interval by Blocks interaction, $F(6,135)=3.76$, $\mathrm{p}<.05$. Shock rate was a decreasing function of Intensity, Blocks, and, initially, S-S Interval. No differential effects for S-S Interval occurred during the latter part of the session. Profiles of the response and shock rates for the shock intensities are displayed in Figure 1.
A Pearson product moment coefficient of correlation (one-tailed test) between rate of jumping and response rate during the initial $15 \mathrm{~min}$ of training was significant, $r(52)=.46, p<.01$, as was the correlation between initial rate of rearing and the initial response rate, $r(52)=.23, p<.05$.

\section{EXPERIMENT 2}

Although the height of the lever is often reported, it has never been investigated as a variable in avoidance acquisition. In Experiment 2, the relationship between shock intensity and initial leverpress acquisition was investigated during an initial $60-\mathrm{min}$ training session with two lever positions. Preliminary investigation indicated that leverpressing was acquired with difficulty at intensities less than $1.0 \mathrm{~mA}$ (.6 and .8 $\mathrm{mA}$ ) when both lever positions were used; this necessitated the use of $1.0-\mathrm{mA}$ intensity as the weak and 2.0-mA intensity as the moderate shock level. The relationship between the defensive response measures and response rates at both lever positions was determined by correlational analysis.

\section{Method}

Subjects. The rats were 24 experimentally naive male albinos shipped from Sprague-Dawley, Inc., of Madison, Wisconsin, at 57 days of age. Upon arrival, the animals were isolated in

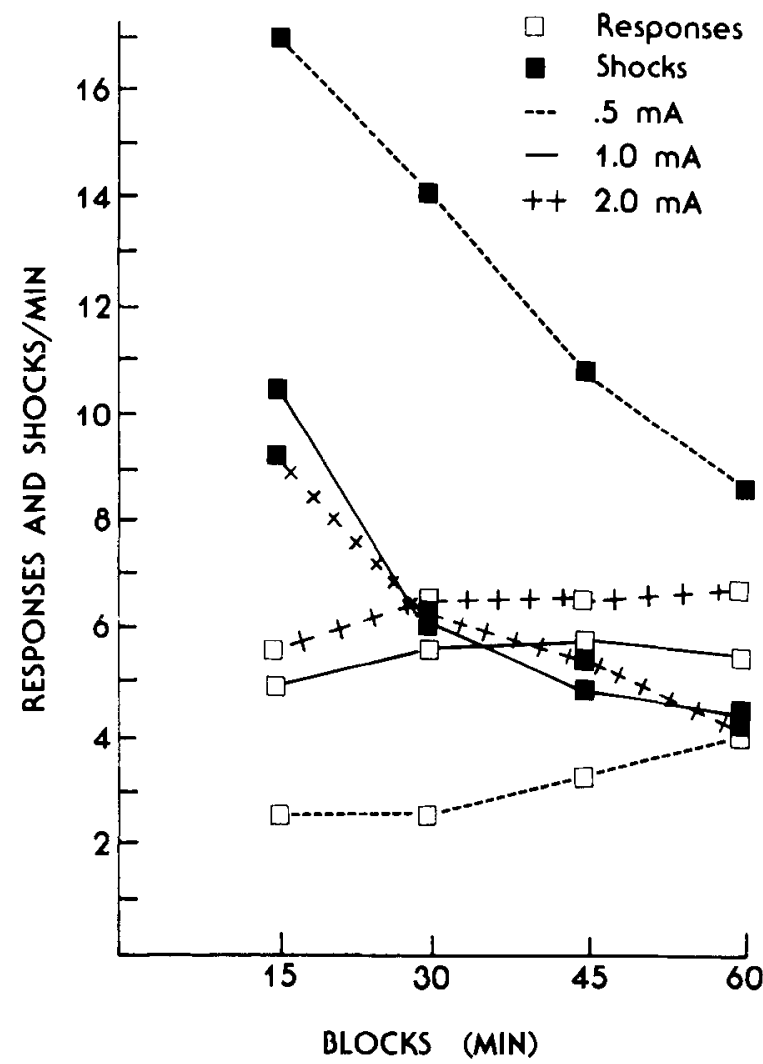

Figure 1. Acquisition of leverpressing as a function of shock intensity. 
individual cages $(24.13 \times 17.78 \times 17.78 \mathrm{~cm})$ and maintained on ad-lib food and water. They were 75-87 days of age at the start of training.

Apparatus. The apparatus employed in Experiment 1 was used with modifications as follows: (1) An additional lever was mounted in the right half of the chamber, $.32 \mathrm{~cm}$ from the side and $3.02 \mathrm{~cm}$ above the grid floor. Both levers were retractable, with only one lever protruding during the session. (2) Translucent sheets, which permitted light to enter the subchamber, covered the outside of the acrylic sheets to minimize visually oriented escape responses that might interfere with leverpressing.

Procedure. A 2 by 2 by 4 factorial design was employed with Shock Intensity (1.0 and $2.0 \mathrm{~mA})$, Lever Position (3.02 and $16.83 \mathrm{~cm}$ above grid), and Blocks (15 min) of training as factors. The animals were trained on Sidman avoidance with an S-S interval of $3 \mathrm{sec}, \mathrm{R}-\mathrm{S}$ interval of $20 \mathrm{sec}$, and shock duration of $.5 \mathrm{sec}$. Each session was conducted in the same manner as in Experiment 1 , and with the same response measures recorded.

\section{Results}

Data for the defensive response measures were analyzed by a 2 by 2 (Intensity by Position) ANOVA and data for the performance measures by a 2 by 2 by 4 (Intensity by Position by Blocks) ANOVA with repeated measures. The Pearson coefficients of correlation between the observers for jumping and rearing were .98 and .98 , respectively.

For the defensive response measures, analysis of jumping revealed a significant effect for Intensity, $F(1,20)=6.96, p<.05$, Position, $F(1,20)=16.40$, $\mathrm{p}<.01$, and their interaction, $\mathrm{F}(1,20)=5.35$, $\mathrm{p}<.05$. The mean at $2.0 \mathrm{~mA}(3.88)$ was significantly greater than at $1.0 \mathrm{~mA}(1.24), \mathrm{p}<.01$; however, no difference was found at the low position (.32 and .49 at 1.0 and $2.0 \mathrm{~mA}$, respectively). Analysis of rearing indicated a significant effect for Position, $F(1,20)=14.56, p<.01$, with a greater mean at the high (19.93) than at the low position (5.06).

Analysis of response rate indicated significant effects for Intensity, $F(1,20)=11.31, p<.01$, Position, $F(1,20)=5.89, \mathrm{p}<.05$, and their interaction, $F(1,20)=7.26, p<.05$. The intensity effect was significant at the high position, $\mathrm{p}<.01$, with a greater response rate at $2.0(9.74)$ than at $1.0 \mathrm{~mA}$ (3.92); the intensity effect was not significant at the low position (4.18 and 4.82 at 1.0 and $2.0 \mathrm{~mA}$, respectively). A significant Position by Blocks interaction, $F(3,60)=7.97, p<.01$, with simple effects analysis indicated a significant block effect at the high position, $p<.01$, but not at the low position.

Analysis of shock rate indicated a significant effect of Intensity, $F(1,20)=10.91, p<.01$, with a greater shock rate at $1.0(9.20)$ than at $2.0 \mathrm{~mA}(5.32)$. Significant effects were found for Blocks, $F(3,60)=4.91$, $p<.05$, and the Position by Blocks interaction, $F(3,60)=10.68, p<.01$. Simple effects analysis indicated a significant effect of Blocks at the high position, $p<.01$, but not at the low position. Profiles of the response and shock rates for the lever positions are displayed in Figure 2.

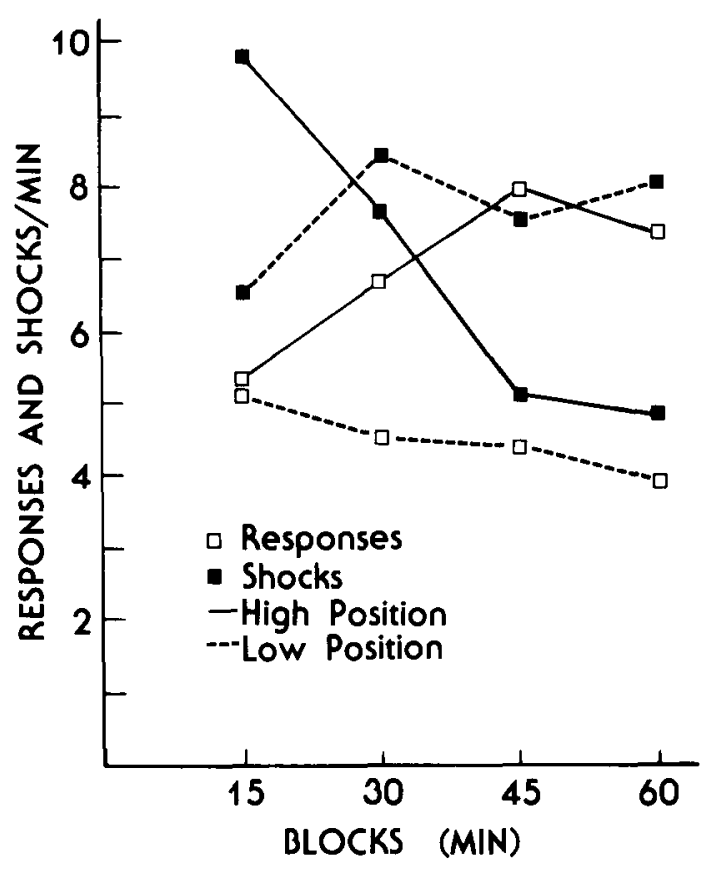

Figure 2. Acquisition of leverpressing as a function of lever position.

Pearson product moment coefficients of correlation between the initial 15 -min response rate and initial rate of jumping for low and high lever positions were $r(12)=-.14$ and $r(12)=.39$, respectively, $p<.05$. The coefficients of correlation between the initial response rate and initial rate of rearing for low and high lever positions were $r(12)=$ .28 and $\mathrm{r}(12)=.18$, respectively, $\mathrm{p}<.05$.

\section{DISCUSSION}

The following conclusions seem warranted:

(1) When relatively short intervals are used, variation in S-S interval has little effect on jumping, rearing, and leverpress acquisition. These results for response rate support those of Leaf (1965) and Stone (1966). The significant differences found initially for the shocks received measure disappeared after 30 min of training. Therefore, it was assumed that the initial effect was an artifact in that the higher rates of shocks received at shorter S-S intervals were due to higher rates of presentation. Stone has reported a similar finding concerning this artifact with relatively long intervals ( 5 and $10 \mathrm{sec}$ ).

(2) The defensive response category of jumping is an increasing function of shock intensity, supporting earlier research (Kimble, 1955; Trabasso \& Thompson, 1962). Rearing appears to be an increasing function of shock intensity at lower intensities $(.5$ and $1.0 \mathrm{~mA})$. The results suggest partial suppression of rearing at higher intensities $(2.0 \mathrm{~mA})$, indicating that facilitated leverpressing at higher intensities must be due to increased jumping rather 
than rearing; the importance of jumping in this facilitation has been reported by Riess and Farrar (1972). The intensity effect holds only when the lever has a relatively high position.

The procedure employed by Kimble and by Trabasso and Thompson was to record unconditioned responding directly elicited by shock. In the present study, any jumping and rearing was recorded, whether directly elicited or occurring in the absence of shock, since this responding may also be instrumental in attaining reinforcement. In fact, jumping and rearing occurred between shocks, during the R-S interval, or after receiving several shocks in succession. The initial reaction to shock appeared to be a position in which all four feet alternated in making contact with the grid (resembling "running in place"). Although the spatial restriction used here was designed to eliminate running, attempts to run were apparent. Attempted running often resulted in contact with the lever at the low position and fewer shocks were received; consequently, less jumping and rearing occurred at the low position. When rats are spatially restricted, running is highly compatible with the avoidance topography of the low lever position. In contrast, running is not compatible with the high lever avoidance topography and therefore does not facilitate responding.

(3) When the rat's activity is resiricted to a small area, leverpress acquisition on a Sidman avoidance schedule is an increasing function of shock intensity. This relationship was limited to the higher lever position $(16.83 \mathrm{~cm})$, supporting the results of Riess and Farrar, who used a $9.0-\mathrm{cm}$ lever position. When a low position is used, with a different "avoidance topography requirement"' (Riess \& Farrar, 1972, p. 352), the increasing function is not apparent.

The increasing function is sharply contrasted with the decreasing function reported in discriminated leverpress acquisition (D'Amato, Etkin, \& Fazarro, 1968; D’Amato, Fazzaro, \& Etkin, 1968). Leverpress acquisition may be facilitated in both situations due to exposure to the avoidance contingency early in training. In discriminated avoidance, this exposure is enhanced by anticipatory responses (leverpresses during the CS-US interval) which are inversely related to shock intensity (D'Amato, Etkin, \& Fazzaro, 1968), with higher intensities promoting response suppression. In Sidman avoidance, exposure to the avoidance contingency is enhanced by shock-elicited leverpresses which appear directly related to shock intensity (Riess \& Farrar, 1972) and are more probable, initially, when leaping is pervasive.

(4) Bolles' (1970) hypothesis may be invoked to account for this difference. With a high lever position, facilitated leverpressing at higher shock levels is due primarily to increased jumping and rearing- two defensive reactions which are highly compatible with the avoidance topography requirement. The higher shock levels, as indicated in Experiments 1 and 2 , result in responding (jumping and rearing), which is compatible with the avoidance topography. Leverpress acquisition is impeded at lower shock levels due to defensive responding, in the form of running or freezing, which is not compatible with the avoidance topography. Jumping appears to be of greater importance in leverpressing in that "downward excursions" (p. 352) from jumps usually result in a leverpress, as has been reported by Riess and Farrar. Initial leverpress performance is moderately correlated with rate of jumping $(r=.46$ and $r=.39$ in Experiments 1 and 2, respectively). Rearing does not appear to be as important as jumping in facilitating initial leverpressing. Rats often assume an upright position at the lever, but fail to press. Initial leverpress performance shows a weak correlation with rate of rearing $(r=.23$ and $r=.18$ for Experiments 1 and 2, respectively).

A more general avoidance topography requirement is associated with the low lever position. Rearing, jumping, and a more general activity resembling running may be instrumental in leverpressing with a low lever position. Most leverpresses at the lower position appear to be the result of this general activity ("running") rather than a consequence of rearing or jumping. Little difference exists between low- and high-intensity levels because the initial reaction results in the leverpress response, and rearing and jumping do not interfere because shock is usually terminated within a short time. Some interference is suggested in the negative relationship between rate of jumping and initial response rate $(r=-.14)$. The positive relationship between rate of rearing and initial response rate at the low position is contrary to the negative one expected by Bolles' hypothesis $(r=.28)$. Rearing activity should interfere with manual leverpressing at the low position, thus impairing acquisition.

(5) When activity is restricted to a small area, use of a high lever position facilitates leverpress avoidance learning. Initially, rats responding at the low position received fewer shocks than those at the high position, reflecting greater accessibility and a more general avoidance topography requirement at the low position. Throughout the remainder of the session, rats pressing the higher lever revealed increments in performance in contrast to the decrements of those pressing the lower lever. Apparently a difference in the topography requirement of the high and low positions is a contributing factor. The more general topography requirement at the low position results in more difficulty in discriminating between appropriate and inappropriate responses, since several types of responses with different topographies may be reinforced. A more specific 
topography requirement exists at the high position, hence discrimination is less difficult and learning is facilitated due to rapid extinction of inappropriate responses.

The generality of this conclusion may be limited to spatially restrictive situations. If animals are allowed more spatial freedom, the occurrence of running might increase substantially, thus competing with leaping and rearing tendencies. Consequently, facilitated leverpressing, associated with the high position, would be reduced or eliminated. Riess (1971) has suggested the possibility of running as a dominant tendency in aversive situations. His data, showing more rapid acquisition of hurdle crossing, as compared to leverpressing, certainly supports this notion.

\section{REFERENCES}

Bolles, R. C. Species-specific defense reactions and avoidance learning. Psychological Review, 1970, 77, 32-48.

Bolles, R. C., \& Popp, R. J., JR. Parameters affecting the acquisition of Sidman avoidance. Journal of the Experimental Analysis of Behavior, 1964, 7, 315-321.

Cahoon, D. D., \& Crosby, R. M. A technique for the automatic shaping of escape and avoidance behavior in the operant conditioning chamber. Psychological Record, 1969, 19, 431-432.

D'Amato, M. R., Etkin, M., \& Fazzaro, J. Effects of shock type and intensity on anticipatory responses. Journal of Comparative and Physiological Psychology, 1968, 66, 527-529.

D'Amato, M. R., Fazzaro, J., \& Etkin, M. Anticipatory responding and avoidance discrimination as factors in avoidance conditioning. Joumal of Experimental Psychology, 1968, 77, 41-47.

Kimble, G. A. Shock intensity and avoidance learning. Journal of Comparative and Physiological Psychology, 1955, 48, 281-284.

LEAF, R. C. Acquisition of Sidman avoidance responding as a function of S-S interval. Journal of Comparative and Physiological Psychology, 1965, 59, 298-300.

RIEss, D. Shuttleboxes, Skinner boxes, and Sidman avoidance in rats: Acquisition and terminal performance as a function of response topography. Psychonomic Science, 1971, 25, 283-286.

RIEss, D., \& FARRAR, C. H. Shock intensity, shock duration, Sidman avoidance acquisition, and the "all or nothing" principle in rats. Journal of Comparative and Physiological Psychology, 1972. 81, 347-355.

Stone, G. C. Some factors that influence acquisition of freeoperant avoidance behavior. Psychological Reports, 1966, 18. 383-396.

Trabasso, T. R., \& Thompson, R. W. Shock intensity and unconditioned responding in a shuttlebox. Journal of Experimental Psychology, 1962, 63, 215-216.

(Received for publication June 14, 1976; revision accepted November 14, 1976.) 